\title{
A ANOREXIA, O OUTRO E O DESEJO
}

\author{
Dayane Costa de Souza Pena ${ }^{1}$ \\ Universidade Federal de São João del-Rei, Brasil \\ dayannepena@hotmail.com \\ ORCID: 0000-0001-9137-3846
}

DOI: 10.17533/udea.affs.v16n31a03

\section{Resumen}

Este artículo pretende elucidar la anorexia en la estructura histérica, destacando la relación particular que el sujeto establece con el Otro y con su deseo en la formación de ese síntoma. La anorexia es tomada por el sujeto como una estrategia radical de separación del Otro, una vía de altos costos para el sujeto, cabe resaltar, que muchas veces paga el precio de la propia vida. Tal posicionamiento de la anoréxica apunta, de esa forma, hacia la paradojal radicalidad de su sujetamiento al deseo del Otro.

Palabras claves: Anorexia, deseo, Otro, sujetamiento, separación.

\section{ANOREXIA, OTHER, AND DESIRE}

\section{Abstract}

This paper intends to elucidate anorexia in the hysterical structure, emphasizing on the particular relationship that the subject establishes with the Other and desire in the creation of that symptom. Anorexia is taken by the subject as a radical strategy of separation from the Other, a way of high costs for the subject, and it is worth mentioning that many times it is paid with their own life. Such posture of the anorexic points, in that way, towards the paradoxical radicality of their attachment to the Other's desire.

Keywords: anorexia, desire, Other, attachment, separation.

1 Psicóloga e Mestra em Psicologia pela Universidade Federal de São João del-Rei. Docente do curso de Psicologia da UNIDOCTUM. 


\section{L'ANOREXIE, L'AUTRE ET LE DÉSIR.}

\section{Résumé}

Ce texte a pour dessein d'élucider gie que le sujet doit souvent payer au l'anorexie dans la structure hysté- prix de sa vie. Ce positionnement de rique, soulignant la relation particu- l'anorexie signale ainsi la radicalité lière que le sujet établit avec l'Autre paradoxale de son assujettissement et avec son désir dans la formation au désir de l'Autre. de ce symptôme. Le sujet adopte l'anorexie en tant que stratégie radi- Mots-clés : anorexie, désir, Autre, ascale de séparation de l'Autre, straté- sujettissement, séparation.

Recibido:07/01/2019 • Aprobado:24/04/2019 


\section{A anorexia em Freud e em Lacan}

Em nossos estudos sobre a anorexia em psicanálise encontramos na obra de Sigmund Freud e no ensino de Jacques Lacan algumas referências sobre esse sintoma. É fato que nem Freud, nem Lacan, se dedicaram exclusivamente ao estudo da anorexia, mas nem por isso eles se abstiveram de dar suas contribuições sobre o assunto, nos deixando valiosas indicações para o desenvolvimento de um trabalho psicanalítico com a anorexia.

As primeiras referências de sobre a anorexia encontram-no caso "Emmy von N." (2006/1895), no qual fala de uma anorexia histérica, aproximando esta a um sintoma de conversão e no "Rascunho G" (2006/1895a), onde associa a anorexia à melancolia, logo, afirma que a perda de apetite das pacientes decorreria de uma perda de libido. Já alguns anos mais tarde, em "História de uma neurose infantil" (2006/1918[1914]), Freud retoma a anorexia e a define como uma neurose que se manifesta em meninas durante a puberdade, e que expressaria uma aversão à sexualidade, destacando ainda a sua conexão com a fase oral.

A partir de seus casos, Freud nos evidencia uma articulação entre os sintomas de ordem alimentar, como a anorexia, e a sexualidade, esclarecendo, que a constituição desses sintomas se dá no laço do sujeito com o Outro, pontos que, também, Lacan enfatizará ao falar sobre o tema da anorexia, como veremos a seguir.

Lacan em seu texto Os complexos familiares na formação do indivíduo (1984/1938), no qual situa a anorexia como um dos efeitos traumáticos do desmame. A posição anoréxica remeteria, justamente, a uma fixação no complexo de desmame, como uma tentativa do sujeito de reencontrar a imago materna, mesmo que ao preço da própria morte.

O caráter mortífero da anorexia estaria estritamente ligado ao que Lacan denomina como um “desejo de larva” (1984/1938, p. 26). Segundo Recalcati (2007), o desejo e a larva são duas dimensões antagônicas, pois enquanto o desejo se caracteriza por uma irredutibili- 
dade e por um movimento incessante, eterno; a larva é a ausência de qualquer vitalidade e movimento, ela é exatamente uma condição de não-desejo. Desse modo, ao falar em um desejo de larva presente na anorexia, Lacan refere-se a um desejo paradoxal do sujeito de aniquilação de seu desejo. Nesse caso, a anoréxica almejaria uma re-fusão com o Outro materno, numa tentativa de reencontrar o gozo perdido, de retornar ao nível zero de tensão - princípio de nirvana (Freud, 1920/2006) -, ostentando uma posição fundamentalmente melancólica - semelhante ao que Freud já havia proposto em seu Rascunho G (2006/1895a) -, em que se coloca em luto pelo objeto perdido, e, inconsolavelmente, se sacrifica por reencontrá-lo, num impulso regressivo dirigido à Coisa (das Ding).

Lacan volta a nos falar sobre a anorexia em seu seminário A relação de objeto (1995/1956-1957) e em seu texto "A direção do tratamento e os princípios de seu poder" (1998/1958), agora sob outra perspectiva, em que a anorexia não se apresenta como uma nostalgia do todo, e sim como um meio de separação de um todo que sufoca.

Lacan (1995/1956-1957) assim nos ensina que a anorexia não é um simples não comer, mas sim, um comer nada. Ou seja, não se trata apenas de uma recusa do alimento, o sujeito come algo, ele come nada. E como lembra o autor, este nada que a anoréxica come é algo que existe no plano simbólico e do qual lança mão para inverter a sua relação de dependência perante a mãe, fazendo com que a mãe, antes vista como onipotente, passe, a partir de então, a depender dela.

A recusa da anoréxica, ou melhor, o seu comer nada é, portanto, uma tentativa do sujeito de imputar uma falta ao Outro, na medida em que barra a mãe tida onipotente. A mãe que, como ressalta Lacan (1998/1958, p. 634), diante do apelo pode criar suas próprias ideias a respeito do que a criança pede e/ou precisa, e muitas vezes, responde com objetos sob a marca da necessidade, dando aquilo que tem, empanturrando-a com a "papinha sufocante", numa tentativa de preencher o vazio da boca que a clama, e desta forma "confunde seus cuidados com o dom de seu amor".

Logo, "é a criança alimentada com mais amor que recusa o alimento e usa sua recusa como um desejo (anorexia mental). Limites em que se apreende, como em nenhum outro lugar, que o ódio retri- 
bui a moeda do amor, mas onde a ignorância não é perdoada" (Lacan, 1998/1958, p. 634). Se o Outro apenas dá aquilo que tem, cai na ignorância sobre o desejo, e isto não é perdoado pela anoréxica.

Com base nas referências encontradas em Freud e em Lacan a respeito da anorexia, podemos destacar a importância do desejo na consideração desse sintoma na estrutura histérica. $\mathrm{O}$ desejo surge como algo caro ao sujeito na anorexia, algo pelo qual o sujeito é capaz de padecer, e que em alguns casos é algo que se apresenta com o valor da própria vida. A anorexia é tomada pelo sujeito como uma saída radical para garantir-se desejante e ser reconhecido enquanto tal pelo Outro. Posição esta que não é sem custo para o sujeito, que, em muitos casos, paga o alto preço da própria morte.

Em vista disso, em sua demanda, a anoréxica não requer do Outro unicamente a satisfação de uma necessidade. Uma vez que, a sua demanda, assim como a de todo sujeito, é primordialmente uma demanda de amor e uma busca por um saber sobre o desejo do Outro - do qual seu próprio desejo é dependente.

Lacan, em Os quatro conceitos fundamentais da psicanálise (2008/1964, p. 210), nos diz que diante da angústia gerada pelo enigma do desejo do Outro, o sujeito pode recorrer à fantasia de seu desaparecimento, de sua morte, numa tentativa de saber que lugar ocupa no desejo do Outro. "O primeiro objeto que ele propõe a esse desejo parental cujo objeto é desconhecido, é sua própria perda. Pode ele me perder? (...) - sabemos disso por mil fatos, ainda que fosse pela anorexia mental". Na anorexia a fantasia de morte, por vezes, é levada às últimas consequências pelo sujeito, como uma tentativa de questionar os limites do desejo e do amor do Outro em relação a ele, sujeito -"até que ponto o Outro o quer, qual o limite desse querer" (Silva \& Bastos, 2006, p. 103). Notamos aqui que há um assujeitamento do sujeito anoréxico ao Outro, em que somente pelas suposições acerca do desejo do Outro é que este sujeito pode posicionar o seu desejo.

Para o desenvolvimento deste artigo extraímos do breve levantamento realizado a partir dos textos freudianos e lacanianos, citados acima, alguns pontos teóricos que consideramos estratégicos para a elucidação da anorexia manifesta na estrutura histérica, sobre os quais pretendemos trabalhar de maneira mais detalhada. 
Iniciaremos por abordar o tema da constituição subjetiva e, em seguida, adentraremos no conceito de desejo e a sua articulação com os conceitos de necessidade e de demanda, para, posteriormente, discorrermos sobre os arranjos possíveis ao sujeito diante do enigma do desejo do Outro e da impossibilidade de satisfazer-se plenamente.

\section{A anorexia e a articulação entre necessidade, demanda e desejo}

Ao propormos um trabalho de abordagem da anorexia pela psicanálise, necessariamente estamos tratando do sujeito. $\mathrm{O}$ sujeito, para a psicanálise, não é da ordem natural, biológica, muito menos se trata de uma categoria psicológica como é a personalidade, como também não pode ser reduzido a uma determinação social. O sujeito do qual trata a psicanálise é o sujeito do inconsciente, marcado pela "falta-a-ser" (Lacan, 1998, p. 633) e, portanto, desejante. Ele não nasce com o organismo, mas se constitui, na medida em que ingressa no campo da linguagem, no campo do Outro.

Embora Freud não apresente em sua obra, explicitamente, uma articulação entre o inconsciente e a linguagem, ele nos ensina que o inconsciente se estrutura como um sistema de representações, de traços de memória, de signos de percepção, que se organizam através dos mecanismos de condensação e de deslocamento. Ou seja, nas elaborações de Freud sobre o inconsciente já existem indícios de uma ordem simbólica (Elia, 2010), sendo Lacan o primeiro a extrair as consequências lógicas disto. É na linguística estrutural de Ferdinand de Saussure que Lacan encontra o suporte metodológico necessário para afirmar que o "inconsciente é estruturado como uma linguagem" (Lacan, 2008/1964, p. 199).

A partir das categorias de significante (imagem acústica) e significado (ideia/conceito que se liga à imagem acústica) que constituem o signo linguístico em Saussure, Lacan busca demonstrar o funcionamento do inconsciente, que possui uma lógica própria, da qual Freud (2006/1915a) já havia nos falado. Para isso, foi preciso que Lacan subvertesse a fórmula original do signo escrita por Saussure - significado 
sobre significante (s/S) -, conferindo primazia ao significante e afirmando a sua autonomia perante o significado. Assim, a fórmula do signo que interessa à psicanálise passa a ser escrita com o significante sobre o significado (S/s). Pois Lacan entende que no nível do inconsciente prevalece a articulação entre significantes, de maneira tal que estes se agrupem em forma de cadeia. Dessa forma, um significante se liga a outro, e outro, infinitamente, estabelecendo entre eles uma ordem, o que produz um significado. O significado só se dá no a posteriori da articulação entre os significantes, ele não existe antes disso. Isso fica claro, quando, por exemplo, uma frase qualquer é enunciada. O sentido do primeiro significante somente será conhecido quando o último significante for articulado, em retroação (Quinet, 2008).

O sujeito como aquele que se constitui na linguagem, deixando-se marcar pelo significante e assumindo a sua estrutura, somente tem acesso a esse campo simbólico pela via do Outro. Freud, no texto "Projeto para uma psicologia científica" (2006/1950[1895]), já nos dá referências da existência de uma dimensão da alteridade na constituição do sujeito, quando ele nos fala sobre a primeira experiência de satisfação, momento de fundação do aparelho psíquico.

Segundo Freud (2006/1950[1895], p. 370), o ser humano nasce sob uma condição de desamparo radical, na medida em que é inicialmente incapaz de realizar qualquer ação específica que garanta a sua sobrevivência, sendo necessário para isso a ajuda alheia. O que resta ao bebê, nesse primeiro momento, é o grito, "e essa via de descarga adquire, assim, a importantíssima função secundária da comunicação". É perante o grito que surge um outro, próximo, que poderá se apresentar na figura da mãe, e vêm em socorro ao recém-nascido desamparado, interpretando o grito - que até então não passava de uma descarga motora ineficaz em aliviar a tensão, desprovido de qualquer sentido - como um pedido, e prestando os cuidados que julga necessários. Podemos dizer, baseados nas contribuições de Lacan ao tema, que juntamente aos seus cuidados, a mãe introduz toda uma ordem simbólica sob a marca do significante, assumindo a posição de Outro - grande Outro.

Conforme Freud (2006/1950[1895], p. 384), é o encontro com o outro que permite as primeiras inscrições psíquicas e, consequentemente, uma primeira apreensão da realidade pelo sujeito, funda- 
mentando, assim, o que o autor denomina de complexo do próximo (Nebenmensch). Segundo Freud, o complexo do próximo se dá nas primeiras experiências de satisfação e "se divide em dois componentes, dos quais um produz uma impressão por sua estrutura constante e permanece unido como uma coisa, enquanto o outro pode ser compreendido pela atividade de memória". Podemos entender que por um lado há certo reconhecimento do próximo pelo sujeito, na medida em que restam traços da experiência que se inscrevem no sistema de memória, mas, por outro lado, existe algo que resiste e escapa a este reconhecimento como uma Coisa (Ding).

Lacan, em seu seminário A ética da psicanálise (2008/1959-1960, p. 67), ao retomar o texto freudiano nos diz que "o Ding é o elemento que é originalmente, isolado pelo sujeito em sua experiência do Nebenmensch como sendo, por natureza, estranho, Fremde". O Ding se apresenta, desse modo, como aquilo que do Outro é inapreensível, o que provoca estranheza e até mesmo causa horror no sujeito. Contudo, o Ding é também aquilo que movimenta todo o campo das representações já constituídas, visto que é em torno desse furo na concepção do Outro que o sujeito se organiza e se constitui como desejante.

O conceito de desejo, para Freud, no texto "A interpretação dos sonhos" (2006/1900), estaria estritamente relacionado ao movimento que o sujeito realiza numa tentativa de reencontro com o objeto perdido, ou melhor, trata-se de uma tentativa de reencontro com a suposta satisfação proporcionada por este objeto. Uma das primeiras tentativas do sujeito em reaver a satisfação original acontece, segundo Freud, por meio da alucinação. Da primeira experiência de satisfação restaram traços mnêmicos da percepção do objeto, que serão reinvestidos e reenvocados quando surgir uma nova impulsão psíquica. O bebê, assim, cria uma nova percepção do objeto, alucinando, e isso garante a ele certa satisfação. Porém, a satisfação obtida pela via da alucinação não é a esperada - lembrando que a representação daquele primeiro objeto de satisfação é sempre faltosa, o que torna o objeto inatingível, estando este perdido para sempre. Diante disso, o psiquismo é levado a conceber uma realidade externa e a promover alterações nesse meio, mesmo que estas lhes sejam desagradáveis (Freud, 2006/1911). Ao sujeito, ainda incapaz de realizar qualquer ação específica, resta o apelo direcionado ao 
Outro, que num primeiro momento interpretou o grito como uma demanda de cuidados, como único meio de promover tais alterações e obter certa satisfação.

Percebemos que desde o início no sujeito a necessidade está obrigada a ter certa relação com significante, o que evidentemente a modifica, subverte-a. A necessidade, dessa maneira, só pode chegar a nós refratada, fragmentada, despedaçada, ao sofrer os efeitos dos mecanismos psíquicos - deslocamentos, condensação, etc. -, ou seja, ao se articular na linguagem. Não existe, portanto, um estado originário, nem necessidade pura no sujeito, desde sempre se trata de desejo. A necessidade apenas é experienciada como um momento mítico, pois nenhum ser de linguagem consegue ter acesso a ela enquanto tal (Lacan, 1999/1957-1958).

Na anorexia torna-se ainda mais evidente a subversão da necessidade no sujeito pelo fato deste se encontrar imerso no campo significante. O sujeito na anorexia abdica do alimento como objeto de necessidade, essencial à sobrevivência do organismo, demonstrando que para ele não se trata apenas disto - comer para sobreviver -; é preciso que haja um para-além da necessidade, é preciso que haja desejo. $\mathrm{O}$ alimento não serve apenas para estancar o impulso da alimentação, ele adquire um valor simbólico para o sujeito, e como tudo que possui um valor, ingressa na relação das trocas entre o sujeito e o Outro, ultrapassando assim a dimensão simplesmente biológica.

O fato de o sujeito tomar a palavra e enunciar, por exemplo, "preciso comer", nos aponta não mais para o registro da necessidade, mas sim para o registro da demanda. Lacan (1999/1957-1958, p. 91) define a demanda como sendo "aquilo que a partir de uma necessidade, passa por meio do significante dirigido ao Outro". A demanda do sujeito não visa apenas o objeto de necessidade que supostamente pede, ela sempre se dirige ao Outro como o lugar de onde virá a resposta para seu pedido. A demanda do sujeito é assim um apelo à presença ou à ausência desse Outro que tem o privilégio de atendê-lo ou não. É a partir desse privilégio do Outro, de impor sua presença ou sua ausência à demanda, que a sua resposta é considerada como signo de amor. Logo, toda demanda é, acima de tudo, demanda de amor (Lacan, 1998/1958a). 
A originalidade da demanda diante da necessidade está em sua incondicionalidade, justamente por ser ela sempre uma demanda de amor, que remete a um jogo simbólico com o Outro. Dessa forma, uma vez que a necessidade está obrigada a passar pelo filtro da demanda, no plano da incondicionalidade, algo dela se perde, pois não é possível uma sobreposição completa entre ambas as dimensões. E isso que é perdido, de acordo com Lacan (1999/1957-1958, p. 395), só pode ser reencontrado no para-além da demanda. Então, nós temos aqui um resto, "resultado da subtração por assim dizer, da exigência da necessidade em relação à demanda de amor", que é outra coisa, e que chamamos de desejo.

Para Lacan (1998/1958), o desejoé, portanto, aquilo que se produz no para-além da demanda, na medida em que esta última desbasta a necessidade que a ela está submetida, deixando um resíduo que não se satisfaz - a própria origem do desejo. Mas também, o desejo é aquilo que se cava no para-aquém da demanda, já que como demanda incondicional de presença e de ausência, ela traz à tona a falta-a-ser, a falta constituinte do sujeito enquanto tal. E, por isso, através da demanda o sujeito sempre almeja receber do Outro seu complemento. No entanto, o ser também falta ao Outro, só sendo possível a este dar aquilo que ele não tem, na forma de seu amor.

Podemos notar que a articulação do desejo na demanda faz dela estruturalmente insatisfeita. Por mais que o pedido do sujeito seja atendido nos mínimos detalhes, que o suposto objeto demandado seja prontamente ofertado, nunca se fica satisfeito, e logo novas e incessantes demandas são criadas, pois o que está em causa não é algo passível de plena satisfação, trata-se a todo momento de desejo, como desejo de outra coisa.

O desejo está sob a condição de necessariamente se articular na cadeia de significantes da demanda para obter certa satisfação, isso não significa, contudo, que ele de fato seja articulável. Isto é, por sua própria estrutura, o desejo não pode ser formulado em palavras, não há um significante que possa expressá-lo (Lacan, 1999/1957-1958). É nos espaços entre os significantes que o desejo faz sua morada, é por onde ele desliza e circula sob efeito metonímico; só podendo, em vista disso, ser apreendido naquilo que não cola, nas faltas e nos tropeços que se apresentam no discurso (Lacan, 2008/1964). O sujeito, então, 
se vê diante da impossibilidade de pela fala dizer tudo o que quer, e ainda, de sua sujeição àquilo que no discurso se articula a sua revelia, sem a sua consciência, mas certamente com sua participação ativa, uma vez que ele é sujeito do inconsciente (Elia, 2010).

O Outro é propriamente o lugar da linguagem, o lugar da outra cena - eine andere Schauplatz - da qual nos fala Freud (2006/1900), de onde provêm os primeiros significantes e para onde são direcionadas as demandas do sujeito que anseiam por respostas. Este lugar do Outro, é inicialmente, encarnado pela mãe (ou qualquer pessoa que se ocupe da função de prestar os primeiros cuidados da criança), ou seja, por um outro ser de linguagem, e que, desse modo, se encontra subordinado à ação do significante. Aqui, o Outro é marcado pela falta(-a-ser), como já havíamos mencionado, pois também falta a ele o significante último que daria conta de todas as questões do sujeito, aquele que seria capaz de traduzir o que é o desejo.

Somente a partir de um Outro cindido pela ação do significante é que o sujeito pode reconhecer que também ele está sob marca do significante. Segundo Lacan (1998/1958, p. 635), o sujeito apenas consegue "encontrar a estrutura constitutiva do seu desejo na mesma hiância aberta pelo efeito dos significantes naqueles que para ele representam o Outro". Isto é, o sujeito percebe naquilo que falha no discurso do Outro que existe ali um para-além ou um para-aquém da demanda, que é irredutível ao significante e que não se satisfaz. É frente ao desejo barrado do Outro que o sujeito identifica o seu próprio desejo como igualmente barrado, um desejo insatisfeito (Lacan, 1999/1957-1958).

É possível que na anorexia o sujeito se depare com um Outro materno sempre disposto a atender suas necessidades, que procura garantir que nada lhe falte. Um Outro que, retomando ao que Lacan (1998/1958, p. 634) nos ensina, interpreta a demanda do sujeito apenas no nível da necessidade e, consequentemente, em resposta dá aquilo que tem, empanturrando o sujeito com a "papinha sufocante (...), ou seja, confunde os seus cuidados com o dom de seu amor". Mas, o sujeito anoréxico não quer o que o Outro tem, ele quer exatamente o oposto, quer o que o Outro não tem. Nesse caso, é preciso que o objeto ofertado ao sujeito, como é o alimento, seja também 
prova do amor da mãe, trazendo consigo as insígnias do desejo desta última, a marca da sua falta (Recalcati, 2007).

A grande questão do sujeito na anorexia é como inscrever no Outro uma falta (Recalcati, 2007). A anoréxica come nada se recusando a satisfazer à demanda materna, e assim, presentifica a falta nesta relação com o Outro, dizendo a este que busque um desejo para além dele, sujeito. Com isso, esse sujeito sairia da suposta função de tampão da falta do Outro, sendo capaz de encontrar a sua via rumo ao desejo (Lacan 1998/1958).

A distinção entre necessidade, demanda e desejo, articulada por Lacan, é bastante cara a nossa discussão sobre a anorexia histérica, já que por meio dela apontamos que se, por um lado, pode haver um Outro sempre disposto a atender à necessidade de alimento, por outro lado, apontamos também que há um sujeito que toma o alimento como o suposto objeto do desejo. Isto é, o sujeito credita ao objeto oferecido pelo Outro - no caso o alimento - o poder de satisfazer, de sufocar o desejo. Como vimos, a necessidade pode ser satisfeita, mas o desejo não se liga a nenhum objeto específico e/ou natural, ele está sempre em deslocamento.

Para elucidar a constituição do sujeito pelo desejo do Outro, valer-nos-emos, a partir de agora, das elaborações freudianas e lacanianas acerca do complexo de Édipo, como uma via para pensarmos o assujeitamento radical do sujeito anoréxico ao desejo do Outro materno, concomitantemente, a uma tentativa de separação deste Outro, igualmente radical.

\section{A anorexia frente ao desejo do Outro}

Lembremos que o sujeito só pode ser concebido a partir do campo do Outro, como lugar da linguagem e que é anterior a sua própria existência. Antes mesmo do nascimento da criança já se fala dela, atribuem-lhe um nome, uma religião, uma nacionalidade, etc., isto é, há um discurso que a precede. Dessa maneira, ao nascer, a criança está de antemão imersa em um mar de linguagem, na forma de todos estes significantes dos quais ela vem sendo investida. No entanto, para se 
constituir propriamente como um sujeito da linguagem é preciso que a criança escolha - mesmo se tratando aqui de uma escolha forçada, mas ainda sim uma escolha - se assujeitar ao Outro, se alienando aos significantes deste, ao custo da perda de seu ser.

Já nas primeiras experiências de satisfação vemos que a mãe, ocupando o lugar de Outro primordial, é quem oferece uma interpretação ao grito do bebê, garantindo-lhe o status de demanda, e ela faz isso no nível do desejo - "Ele chora porque me quer por perto", por exemplo. Assim, a demanda que é conferida à criança, ao ser significada pela mãe, retorna a ela trazendo traços do desejo desta última (Dias, 2009). A criança que, a princípio, se encontra numa condição de prematuridade tanto motora quanto simbólica, revela ser completamente dependente do desejo dessa mãe. Logo, nesse momento inicial, o desejo do qual a criança é investida é resultado do desejo do Outro materno.

Freud, em seu texto "Três ensaios sobre a teoria da sexualidade" (2006/1905a, p. 211), ressalta que toda a conduta materna de cuidados e amor para com a criança tem origem na própria vida sexual da mãe. Não é sem motivo que a mãe "acaricia, beija e embala [a criança], e é perfeitamente claro que a trata como o substituto de um objeto sexual legítimo". A mãe, marcada por seu Édipo, conserva em seu inconsciente o desejo de ter o falo, e de certa forma ela o satisfaz por meio de um filho identificado ao falo (Dias, 2009). Conforme Freud em “A dissolução do complexo de Édipo" (2006/1924, p. 198):

A renúncia ao pênis não é tolerada pela menina sem alguma tentativa de compensação. Ela desliza - ao longo de uma equação simbólica poder-se-ia dizer - do pênis para o bebê. (...) Os dois desejos possuir um pênis e um filho - permanecem fortemente catexizados.

Para a mãe, como para todo sujeito que fez sua passagem pelo Édipo, o falo está simbolizado, tratando-se, portanto, de um objeto metonímico, circulante, significante da falta que vem estruturar o desejo, e, assim sendo, passível de se deslocar de uma coisa, que possa representá-lo, para outra. É como bem vemos em Freud (2006/1924) na citação acima, a menina pode substituir o seu desejo de possuir um pênis para o de ter um bebê, sempre almejando o ideal de ter o falo. 
A criança desde muito cedo consegue vislumbrar que "o desejo da mãe é o falo" (Lacan, 1998/1958a, p. 700), e logo quer fazer-se de falo para satisfazê-lo. Esse momento é correspondente ao que Lacan (1999/1957-1958, p. 188) designa como o primeiro tempo lógico do Édipo; nele, a relação estabelecida pela criança não é para com a mãe, objeto primordial, mas para com o desejo desta. Há, aqui, um desejo de desejo, em que o desejo da mãe pode ser desejado pela criança. “O que deseja o sujeito? Não se trata da simples apetência das atenções, do contato ou da presença da mãe, mas da apetência de seu desejo". Entre a criança e a mãe existe mais do que apenas satisfações e frustrações, há a descoberta do desejo da mãe e do seu objeto. E é na medida em que o falo é localizado como objeto privilegiado no desejo materno, que se efetua a identificação imaginária do sujeito com o mesmo. A criança anseia por satisfazer o desejo da mãe, ainda sustentando uma ilusão narcísica de completude, e desse modo, se coloca na posição de ser ou não ser o objeto de desejo desta, isto é, ser ou não ser o falo.

E ao querer constituir-se como único objeto do desejo materno, a criança acaba por se subordinar àquela que é a lei da mãe, lei que se fundamenta no simples fato de a mãe ser um ser de linguagem. E segundo nos ensina Lacan (1999/1957-1958: 195), esta é uma lei não controlada, caprichosa e onipotente, que se sustenta apenas no bem-querer ou malquerer da própria mãe. Em vista disso, para Lacan, no primeiro tempo do Édipo, "a criança se esboça como assujeito", pois ela fica inteiramente assujeitada aos caprichos do Outro materno de quem é dependente.

Para que a criança não seja pura e simplesmente um assujeito posição esta que pode lhe ser extremamente angustiante - é preciso que exista um para-além da mãe. E para atingir este para-além é necessário que algo se estabeleça e faça mediação entre a mãe e o seu objeto de desejo, o falo. Esta mediação é dada, mais precisamente, por aquele que venha a ser o representante da posição do pai na ordem simbólica. É propriamente no segundo tempo do Édipo que o pai - que no primeiro tempo do Édipo ainda se encontrava velado - desponta, por meio do discurso materno, como interventor no triângulo imaginário - mãe-criança-falo - sob a forma da privação (Lacan, 1999/1957-1958). 
É por já ter ocorrido uma primeira simbolização que o desejo da criança então articulado em demanda se dirige à mãe como o primeiro objeto de apelo, esta última responde a seu critério à demanda, seja com a sua presença ou com a sua ausência. E dessa forma, a mãe é instituída pelo sujeito como "aquele ser primordial que pode estar presente ou não" (Lacan, 1999/1957-1958, p. 188). É quando a mãe se faz faltar, que para o sujeito surge a questão do que ela pode desejar de diferente dele - "Há nela [mãe] o desejo de Outra coisa que não o satisfazer o meu próprio desejo, que começa a palpitar para a vida" (Lacan, 1999/1957-1958, p. 189).

No segundo tempo lógico do Édipo, a criança pode apreender a existência de algo fora dela que motive as idas e vindas da mãe, desvendando que "o significado das idas e vindas da mãe é o falo" (Lacan 1999/1957-1958, p. 181). Com isso, a criança vê-se abalada na sua posição de falo materno, já que a mãe se dirige a um outro que não ela, o pai, para obter certo acesso a seu objeto de desejo. Então, na medida em que o desejo da mãe se volta para o pai, o sujeito é convocado a abdicar do lugar de ser o falo da mãe, e mais, ainda num nível imaginário, o pai é instaurado como aquele que é o falo. Nesse momento, o pai surge como um rival, terrível e onipotente, que priva a mãe do seu objeto de desejo e, logo, interdita a mãe enquanto objeto para o filho.

Para o sujeito, a entrada da lei se faz conforme ele "descobre que o desejo da mãe é submetido à instância paterna, ou seja, que a mãe é dependente do pai e, portanto, reconhece a lei do pai como mediatizando o seu próprio desejo" (Dias, 2009, p. 69). O reconhecimento da lei do pai, enquanto uma lei à qual a mãe se remete, está estritamente ligado ao fato de a criança poder identificar que o desejo da mãe é dependente de um objeto que o Outro não mais o é, mas que supostamente o Outro tem ou não tem. Dessa maneira, o pai é concebido como aquele que possui soberanamente o objeto do desejo materno, deixando, portanto, o lugar de pai imaginário, um rival junto à mãe, $\mathrm{e}$ situando-se no lugar de pai simbólico, um promulgador da lei (Lacan 1999/1957-1958).

É decisiva a relação que a mãe mantém não com a pessoa do pai, mas com a palavra deste no sentido de reconhecer a sua lei. Como mencionamos anteriormente, no primeiro tempo do Édipo o pai está 
velado para o sujeito e, por isso, a questão do falo é apenas referenciada pela mãe. Somente no segundo tempo que o pai então aparece, mediado pela mãe, na medida em que a sua fala vem a intervir no discurso materno. Esta intervenção do pai se dá a título de mensagem para a mãe, e de acordo com Lacan (1999/1957-1958, pp. 209-210), “essa mensagem não é simplesmente o Não te deitarás com tua mãe, já dirigido à criança, mas um Não reintegrarás teu produto, que é endereçado à mãe". É pelo fato de a lei paterna incidir sobre o objeto de desejo da mãe "que o círculo não se fecha completamente em torno da criança", ou seja, é pela assunção da lei que esta última não se torna pura e simplesmente o objeto do desejo materno, e ainda, torna-se possível abrir para uma terceira etapa, em que a criança poderá se tornar outra coisa, que não apenas um assujeito, através da sua identificação com o pai.

No terceiro tempo lógico, o pai se revela como aquele que tem o falo e, desse modo, fica estabelecido que "o pai pode dar à mãe o que ela deseja, e pode dar porque o possui" (Lacan, 1999/1957-1958, p. 200). Se o pai está localizado como o único lugar onde é possível obter certo acesso ao falo, isto é, o pai como detentor absoluto do falo, a criança que então já havia sido compelida pela lei paterna a aceitar não ser o falo, agora também precisa aceitar a possibilidade de não o ter, da mesma forma que a mãe. Aqui, torna-se essencial o reconhecimento, por parte do sujeito, da castração da mãe, a qual servirá de suporte para considerar todo humano como simbolicamente castrado, inclusive ele mesmo enquanto sujeito (Dias, 2009).

Segundo Lacan (1999/1957-1958), a castração é uma ação simbólica, em que o agente que a promove é real, é um pai real que incide a sua lei sobre um objeto imaginário, o falo. Assim, o falo ao ser introduzido como aquilo que pode faltar, ganha uma dimensão simbólica, conforme ingressa e se articula no sistema significante, emergindo ele mesmo como o significante da falta que marca o sujeito.

Nesse tempo, há também a constatação da castração do pai. O pai potente é aquele que tem e não tem o falo. Tendo em vista que ele, como Outro, lugar onde se articula a lei, está igualmente submetido à ação significante. E “o efeito do significante no Outro, a marca que este carrega dele neste nível, representa a castração como tal" (Lacan, 
1999/1957-1958, p. 475). Em outras palavras, o pai, como qualquer sujeito, está subordinado à lei da castração. A partir disso, podemos pensar que o que o pai tem é, na verdade, "o título de propriedade virtual" (Lacan, 1999/1957-1958, p. 210) do falo. E, é em torno do reconhecimento deste título que o pai possui que será construída a identificação do sujeito para com ele, o pai.

É na medida em que aceita a lei do pai, que a criança renuncia a sua identificação ao falo imaginário e passa a se identificar com o pai - esse é o declínio do complexo de Édipo. Sendo que nesse momento não se trata mais da identificação à imagem, mas da identificação àquilo que o sujeito reconhece como insígnias do pai, que se apresentam como ideal para o eu. Dessa forma, o eu do sujeito não é mais só um elemento imaginário em sua relação com a mãe, ele se constitui como um elemento significante, portador de uma dialética, de uma mobilidade, passível de circulação na cadeia significante (Lacan, 1999/1957-1958).

É também o encontro com a lei paterna e, a consequente assunção da falta, com o falo emergindo como significante da falta, o que possibilita ao sujeito entrar na dialética do ter ou não ter o falo. Com isso, o sujeito abandona a sua tentativa de ser o falo materno, como já dissemos, e, então, mobiliza seu desejo para os mais variados objetos, numa busca incessante por ter o falo. Assim, o sujeito, antes na condição de assujeitado à mãe, ascende à posição propriamente de desejante.

Retomando alguns pontos já abordados. A criança, de início, já se defronta com a condição de que nesse mundo simbólico do qual se tornou membro integrante, o desejo de cada um está obrigado à lei do desejo do Outro. Isso porque, o estatuto do sujeito desejante não se dá de forma natural, ele precisa ser constituído e isto só é possível a partir da existência do Outro enquanto lugar da linguagem, de onde partem os significantes que o marcam e o fundam na falta-a-ser. Não há, portanto, desejo senão pela via do desejo do Outro. Somente pela constatação de que ao Outro falta, de que existe sempre um para-além da demanda, um resto não significantizável e que não se satisfaz, que o sujeito pode reconhecer que também ele é faltoso, barrado quanto à satisfação plena pela via da demanda. 
É a partir de uma falta percebida no Outro, daquilo que em seu discurso falha, que o sujeito passa a se perguntar acerca do desejo do Outro - "o que ele quer ao me dizer isso?". Lacan (2008/1964) ressalta que todos os intermináveis questionamentos da criança aos pais, todos os seus "por quês", não são simplesmente uma amostra de curiosidade em relação ao funcionamento das coisas, mas já demonstram uma preocupação com o lugar que ela ocupa em relação ao desejo do casal parental. Nesse caso, existe um apelo ao Outro, em que o sujeito demanda receber dele aquilo que supostamente lhe falta - uma demanda de amor -, começando por uma resposta acerca do seu desejo.

O sujeito está sempre às voltas com o desejo do Outro, como uma tentativa de constituir o seu próprio desejo. E na anorexia vemos que este aspecto constitutivo ganha expressão máxima por parte do sujeito. A anoréxica está sempre buscando localizar no Outro uma falta, para que este se mostre desejante, e ela enfim esteja autorizada a também desejar.

Lacan (1995/1956-1957) afirma que na anorexia o sujeito come nada, e ainda, que ele se utiliza disto como uma tentativa de inverter a sua relação de dependência com a mãe, fazendo com que a esta última, tida como onipotente, passe, então, a depender dele, sujeito. Assim, é através do seu investimento no nada que a anoréxica imputa uma falta ao Outro materno, na medida em que frustra a sua demanda, e que não é qualquer demanda, mas sim a demanda de que ela se alimente. A partir disso, podemos pensar que na anorexia o sujeito toma o alimento ofertado pelo Outro como sendo aquilo que o Outro quer dele, e esta é uma maneira encontrada pelo sujeito de tentar dar sentido ao desejo do Outro, fazendo equivaler o alimento e o desejo deste (Silva, 2007).

Diante da dificuldade e, até mesmo, da impossibilidade de saber sobre o desejo do Outro, o sujeito anoréxico se coloca no lugar de objeto do desejo do Outro, para então lançar mão da fantasia de sua própria morte, como uma forma de se fazer faltar ao Outro, pois desse modo, ele poderia investigar o que é este desejo do Outro e o lugar que ocupa neste desejo, com o anseio de saber sobre o próprio desejo.

Como podemos perceber, a partir das colocações feitas até agora, o sujeito na anorexia se encontra numa posição de assujeitamento 
radical ao Outro, aqui encarnado pela mãe, e, por isso, todo o esforço da anoréxica está na tentativa de desassujeitamento, de separação deste Outro, para assegurar-se desejante. É Recalcati (2007) quem propõe que na anorexia existe uma debilidade na função da metáfora paterna, o que, contudo, não implica na foraclusão do Nome-do-Pai - lembrando que estamos abordando a anorexia na estrutura histérica -, mas se trataria mais de um "defeito" no reconhecimento deste como significante que instaura a lei simbólica, que barra a mãe em seu acesso ao objeto de seu desejo e, que, consequentemente, retiraria o sujeito do lugar deste objeto do desejo materno. Com isso, o sujeito fica à mercê de um Outro onipotente e caprichoso, que só faz valer a própria lei. E é frente à angústia gerada por sua condição de assujeitado ao Outro que a anorexia surge como estratégia subjetiva do sujeito para promover a sua separação.

\section{Considerações finais}

Salientamos, no decorrer desse artigo, a importância do desejo na consideração do sintoma anoréxico na estrutura histérica, pois o desejo surge como algo caro ao sujeito na anorexia. Caro, no sentido de ser algo valioso, porém, também apresenta o sentido de ser algo com alto preço a ser pago. Na anorexia, testemunhamos o sujeito em sua busca constante por afirmar a sua separação e a sua posição de desejante para o Outro. Tal posição não é sem custo para ele que há de pagar um alto preço - dores, inanição, amenorreia e, algumas vezes, a própria morte. Tudo isso desvela também o quão radical é o assujeitamento ao Outro, para que ele precise recorrer a uma tão radical tentativa de separação.

Verificamos ainda que na anorexia há um aprisionamento do sujeito à demanda do Outro, em que a fala deste último é considerada uma verdade sobre o desejo. Para a anoréxica, é como se houvesse a possibilidade de uma plena satisfação pelo objeto da demanda do Outro. Isso implica que o alimento é tomado por ela como sendo o suposto objeto do desejo, como aquilo que o Outro quer dela. Dessa maneira, é para garantir que ao Outro falte, e consequentemente, a ele 
mesmo, que o sujeito anoréxico recusa o alimento e come nada, para só então autorizar-se a desejar.

\section{Referências}

Dias, M. G. L. V. (2009). A identificação e enlaçamento social: a importância do fator libidinal. São Paulo: Escuta / Belo Horizonte: Fapemig.

Elia, L. (2010). O conceito de sujeito. (3a ed.). Rio de Janeiro, Brasil: Jorge Zahar Editor.

Freud, S. (2006/1895). Emmy von N. In S. Freud, Sigmund Freud: Obras Completas (Vol. 2, pp. 82-133). Rio de Janeiro, Brasil: Imago.

Freud, S. (2006/1895a). Rascunho G. In S. Freud, Sigmund Freud: Obras Completas (Vol. 1, pp. 246-252). Rio de Janeiro, Brasil: Imago.

Freud, S. (2006/1900). A interpretação dos sonhos. In S. Freud, Sigmund Freud: Obras Completas (Vol. 5, pp. 371-700). Rio de Janeiro, Brasil: Imago.

Freud, S. (2006/1905a). Três ensaios sobre a teoria da sexualidade. In S. Freud, Sigmund Freud: Obras Completas (Vol. 7, pp. 124-232). Rio de Janeiro, Brasil: Imago.

Freud, S. (2006/1911). Formulações sobre os dois princípios do funcionamento mental. In S. Freud, Sigmund Freud: Obras Completas (Vol. 12, pp. 237-246). Rio de Janeiro, Brasil: Imago.

Freud, S. (2006/1915). O inconsciente. In S. Freud, Sigmund Freud: Obras Completas (Vol. 14, pp. 171-224). Rio de Janeiro, Brasil: Imago.

Freud, S. (2006/1918[1914]). História de uma neurose infantil. In S. Freud, Sigmund Freud: Obras Completas (Vol. 17, pp.15-132). Rio de Janeiro, Brasil: Imago.

Freud, S. (2006/1920). Para além do princípio do prazer. In S. Freud, Sigmund Freud: Obras Completas (Vol. 18, pp.17-78). Rio de Janeiro, Brasil: Imago.

Freud, S. (2006/1924). A dissolução do Complexo de Édipo. In S. Freud, Sigmund Freud: Obras Completas (Vol. 19, pp. 189-199). Rio de Janeiro, Brasil: Imago.

Freud, S. (2006/1950[1895]). Projeto para uma psicologia científica. In S. Freud, Sigmund Freud: Obras Completas (Vol. 1, pp. 346-400). Rio de Janeiro, Brasil: Imago.

Lacan, J. (1984/1938). Os complexos familiares na formação do indivíduo. Rio de Janeiro, Brasil: Jorge Zahar Editor. 
Lacan, J. (1995/1956-1957). O seminário. Livro 4: A relação de objeto. Rio de Janeiro, Brasil: Jorge Zahar Editor.

Lacan, J. (1998/1958). A direção do tratamento e os princípios do seu poder. In J. Lacan, Escritos (591-652). Rio de Janeiro, Brasil: Jorge Zahar Editor.

Lacan, J. (1998/1958a). A significação do falo. In J. Lacan, Escritos (pp. 692703). Rio de Janeiro, Brasil: Jorge Zahar Editor.

Lacan, J. (1999/1957-1958). O seminário. Livro 5: As formações do inconsciente. Rio de Janeiro, Brasil: Jorge Zahar Editor.

Lacan, J. (2008/1959-1960). O seminário. Livro 7: A ética da psicanálise. (2a ed.). Rio de Janeiro, Brasil: Jorge Zahar Editor.

Lacan, J. (2008/1964). O seminário. Livro 11: Os quatro conceitos fundamentais da psicanálise. (2a ed.). Rio de Janeiro, Brasil: Jorge Zahar Editor.

Recalcati, M. (2007). La última cena: anorexia y bulimia. Buenos Aires, Argentina: Del Cifrado.

Silva, A. N., \& Bastos, A. (2006). Anorexia: uma pseudo-separação frente a impasses na alienação e na separação. Psicologia Clínica, 18(1), 97-107. Recuperado em https://dx.doi.org/10.1590/S0103-56652006000100008.

Silva, A. N. (2007). Da demanda ao desejo: a função da recusa na anorexia. Psicanálise \& Barroco 5(1), 121-134. Recuperado em http:/ / www.psicanaliseebarroco.pro.br/revista/revista-v-05-n-01. 